Meta

Journal des traducteurs

Translators' Journal

\title{
Professional Translators' Theorising Patterns in Comparison with Classroom Discourse on Translation: The Case of Japanese/English Translators in the UK
}

\section{Akiko Sakamoto}

Volume 62, numéro 2, août 2017

URI : https://id.erudit.org/iderudit/1041024ar

DOI : https://doi.org/10.7202/1041024ar

Aller au sommaire du numéro

\section{Éditeur(s)}

Les Presses de l’Université de Montréal

ISSN

0026-0452 (imprimé)

1492-1421 (numérique)

Découvrir la revue

Citer cet article

Sakamoto, A. (2017). Professional Translators' Theorising Patterns in Comparison with Classroom Discourse on Translation: The Case of Japanese/English Translators in the UK. Meta, 62(2), 271-288. https://doi.org/10.7202/1041024ar
Résumé de l'article

Si l'on souhaite offrir une formation en traduction préparant les étudiants de manière adéquate à leur future carrière professionnelle, il est important de reconnaître les différentes sous-cultures de la traduction, surtout celles des traducteurs professionnels et des enseignants/chercheurs en traduction. La présente étude décrit la façon dont la sous-culture des traducteurs professionnels guide leur pratique, notamment comment les différents concepts sont utilisés pour justifier leurs traductions. Dix-sept traducteurs professionnels travaillant entre le japonais et l'anglais, tous opérant au Royaume-Uni, ont participé à des interviews sur leurs expériences relatives aux conflits avec leurs clients. Dans cet article, en utilisant l'analyse par théorisation ancrée (Grounded Theory), nous présentons les justifications que ceux-ci avancent pour valider leurs traductions. L'analyse identifie le concept $\mathrm{du}$ " rôle des participants » comme le concept le plus important dans le discours des traducteurs. Elle met également en relief d'autres sous-concepts liés au concept principal de manière complexe. Ces sous-concepts comprennent : « les relations », « la connaissance de la langue », " le temps et l'effort passés », « l'autorité » et " la traduction littérale/naturelle ». Ces concepts des traducteurs interviewés sont comparés au discours tenu en classe sur la traduction : les différences et similarités sont discutées. 


\title{
Professional Translators' Theorising Patterns in Comparison with Classroom Discourse on Translation: The Case of Japanese/English Translators in the UK
}

\author{
AKIKO SAKAMOTO \\ University of Portsmouth, Portsmouth, UK \\ akiko.sakamoto@port.ac.uk
}

\begin{abstract}
If we aim to offer translation education that prepares our students adequately for their future professional career, it is important to recognise the different subcultures of translation, particularly those of professional translators and translation academics/teachers. The present study describes how the subculture of working translators theorise their practice, specifically, what concepts they use when they justify their translations. Seventeen Japanese/English translators, all commercially successful professionals who work in the UK, were interviewed about their experience of conflictive situations with their clients. In this article, I present an analysis of their justifications of their translation choices using a grounded theory approach. The analysis identifies the concept of the Role of Participants as the most prominent concept in the translators' discourse. It also highlights several sub-concepts which relate to the main concept in intricate ways. These sub-concepts include Relationship, Knowledge of Language, Time and Effort, Authority and Natural/Literal Translation. The translators' theorization is compared with classroom discourse about translation and the differences and similarities are discussed.
\end{abstract}

\section{RÉSUMÉ}

Si l'on souhaite offrir une formation en traduction préparant les étudiants de manière adéquate à leur future carrière professionnelle, il est important de reconnaître les différentes sous-cultures de la traduction, surtout celles des traducteurs professionnels et des enseignants/chercheurs en traduction. La présente étude décrit la façon dont la sous-culture des traducteurs professionnels guide leur pratique, notamment comment les différents concepts sont utilisés pour justifier leurs traductions. Dix-sept traducteurs professionnels travaillant entre le japonais et l'anglais, tous opérant au Royaume-Uni, ont participé à des interviews sur leurs expériences relatives aux conflits avec leurs clients. Dans cet article, en utilisant l'analyse par théorisation ancrée (Grounded Theory), nous présentons les justifications que ceux-ci avancent pour valider leurs traductions. L'analyse identifie le concept du «rôle des participants » comme le concept le plus important dans le discours des traducteurs. Elle met également en relief d'autres sous-concepts liés au concept principal de manière complexe. Ces sous-concepts comprennent: «les relations», «la connaissance de la langue», «le temps et l'effort passés», «l'autorité » et «la traduction littérale/naturelle». Ces concepts des traducteurs interviewés sont comparés au discours tenu en classe sur la traduction: les différences et similarités sont discutées.

\section{RESUMEN}

Si nuestro objetivo es formar a los alumnos de traducción para su futura preparación profesional, es esencial reconocer las distintas sub-culturas existentes tanto en el mundo profesional como en el académico. El siguiente estudio describe la sub-cultura utilizada 
por los profesionales de la traducción cuando usan la teoría para referirse a sus prácticas particulares, en concreto en lo que se refiere a la utilización de conceptos para justificar sus traducciones. Para ello, diecisiete traductores profesionales de Reino Unido narraron situaciones conflictivas con clientes durante una serie de entrevistas. En el siguiente artículo, presentamos el análisis de sus justificaciones basándonos en la teoría fundamentada (Grounded Theory). Entre todos los conceptos el de Rol del Participante es el más sobresaliente en el discurso de los traductores. El análisis también subraya la compleja relación de este con otros sub-conceptos tales como: Relación, Conocimiento del Idioma, Tiempo y Esfuerzo, Autoridad y Traducción Literal/Libre. El uso de la teoría por parte de los profesionales se compara con el discurso utilizado en la clase de traducción y las similitudes y diferencias del mismo.

\section{KEYWORDS/MOTS-CLÉS/PALABRAS CLAVE}

translation theory, interviews, discourse analysis, professional translation, pedagogy of translation

théorie de la traduction, entrevues, analyse du discours, traduction professionnelle, pédagogie de la traduction

teoría de la traducción, entrevistas, análisis del discurso, traducción profesional, pedagogía de la traducción

\section{Introduction}

Considering the multifaceted nature of translation as a social activity, it is fair to say that the translation community is not mono-cultural, but is, rather, composed of many different groups of actors. Translation scholars/teachers form one group, and working translators form another. In a discussion on professionalism in translation, Jääskeläinen, Kujamäki, et al. (2011: 149-150) call the attention of scholars and translation teachers to be directed towards the differences between them. Drawing on the concept of a "translation subculture," which builds on the notion of "translation culture" developed by Prunč $(1997,2007)$, they maintain that a translation culture is formed by several subcultures and it is therefore important for research and education that the differences between different subcultures are recognised. According to them, lack of recognition of these differences amongst scholars is skewing research designs and outcomes, particularly in studies of the cognitive processes involved in translation. In education, it is important for teachers of translation to be "sufficiently aware of the norms and expectations that prevail on the translation market to ... prepare our graduates to enter it after graduation" (Jääskeläinen, Kujamäki, et al. 2011: 150).

This article aims to contribute to this line of argument, by identifying the difference between the subculture of academics and teachers and that of professional translators. This will be done by examining how the latter explain their translational practice and then by comparing these explanations with academic theories that are commonly used in classrooms.

\section{Theories in classrooms}

In order to establish which theories and theoretical concepts are introduced to students in higher education translation classes, I undertook a survey of 93 translation teachers in the UK and Ireland who were asked what translation theories they taught 
on translation programmes in the higher education institutions where they worked (Sakamoto 2013). In addition to asking respondents to choose relevant items from the list provided, the survey asked them to specify what theories or theoretical concepts they teach in the free answer space if they are not included in the list. Admittedly, this made the data analysis somewhat complicated: when a theoretical topic or a name of a scholar was provided in the free answer, it was sometimes difficult to judge whether it should be counted as an independent 'theory' or 'theoretical notion' or be considered as part of a larger or similar string of thought. In other words, boundaries of theories and concepts are not quite clear-cut. To deal with this uncertainty, notions or author names which are provided by one respondent only were not counted here. As a result, the survey showed that 39 theories or theoretical concepts were taught on MA and BA courses on translation, and that the following were those most commonly taught (with two sets of ties, thus 12 items all together; the authors in the brackets were included to help the survey respondents relate to the concepts listed).

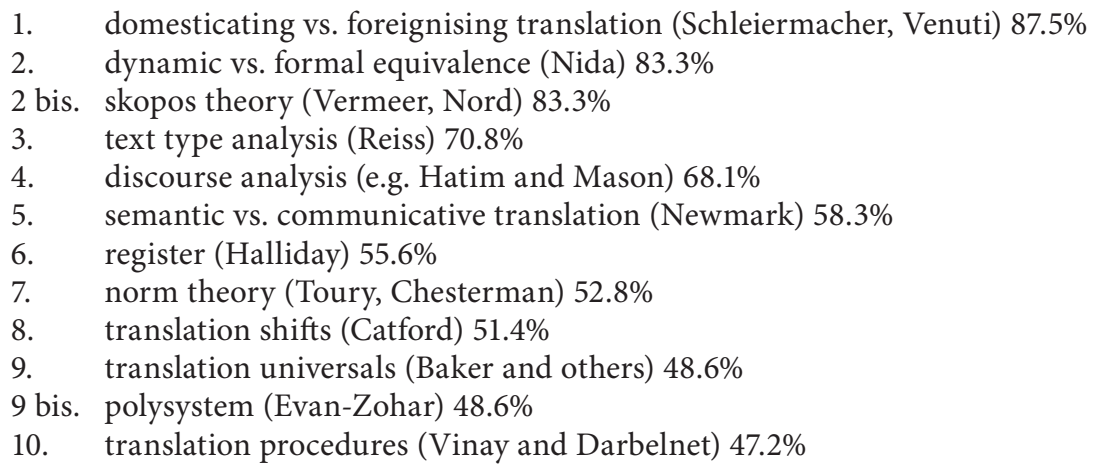

Of course the working of teaching translation is more complicated than just a list of theories. This is because theories can be taught in translation classes for a multitude of purposes. They can be used as a recommendation for a good practice, to explain the history of translation, or to explain practical elements of translation. In the latter case, teaching of theories can support practical modules such as internship (which is becoming increasingly popular in the current context of higher education where the employability of graduates is strongly emphasised). Also, teaching of theories can be offered in different modes depending on the way it is incorporated into the curriculums, and Ulrych (2005: 20) calls for further studies on this topic. The survey undertaken for the purpose of the present study, however, offers a general idea of what theories and concepts are often talked about in translation classrooms, i.e., what discourses of translation are prominent.

\section{Method}

\subsection{Interviews}

The present study adopts the approach of social constructionism, which maintains that knowledge is something "historically and culturally relative," and is constructed through "the goings-on between people in the course of their everyday lives" (Burr 2003: 4). In the context of translation, the principal stance of the present study is the 
belief that " $\mathrm{t}$ ]heory is understanding and explanation, and not only 'something there and established"” (Susam-Sarajeva 2002: 204). In other words, translation theory is not conceived as owned by academics and students, but as something shared by wider participants in translation processes, including translators, who "are theorizing all the time" even though, in most cases, internally and privately (Pym 2010: 1). Theories express the ways of thinking about translation and its practices as told by anybody who is involved in translation. Therefore, interviews were chosen as the method of the study.

The main interview question was "Have your clients ever had disagreements/ issues with the quality of your translation?" This question was chosen because disruption in everyday life, such as having a disagreement with a client, encourages us to try to restore order, and narrative is "a primary means of restoring this sense of order" (Murray 2003: 114). In other words, the topic of disruption was used as a tool to elicit the interviewees' explanation of their sense of order about translation and I understand these explanations as theorizing.

My role as an interviewer was also important. As the interviewees knew my position as a former professional translator who was conducting academic research on translators, I assumed that they would construct their stories in such a way that the stories were understandable and convincing for me. This is what Gubrium and Holstein (2009: 41) call "activation" of a narrative, where "the facts of experience are locally configured as storytellers and listeners actively take part in discursive exchanges." I assumed that this activation would work favourably in this study because in this interview setting the interviewees would give their accounts in the most logical and convincing way. In addition, I possessed what Collins (2007: 30-33) calls "interactional expertise" in translation, which is a kind of expertise that encompasses both the language used in the domain and expertise gained through practical experiences. According to Collins this form of interviews in research elicits rich data.

\subsection{Participants}

Seventeen professional translators took part in the study. Fifteen were freelance translators and two were in-house translators. All of them translate between English and Japanese, into either or both directions. This language combination was chosen because it is my own language combination, enabling me to undertake a detailed investigation of the participants' accounts of linguistic matters. The main criterion for selection of interviewees was whether the person was much in demand in the current translation market (i.e., whether they were successful translators in a commercial sense). This was measured in the case of the freelance translators by the average number of words they translate for remuneration every week (on average 9,920 English source text words or the equivalent number of Japanese words, equating one English word to 1.5 Japanese characters, ranging from 5,000 to 16,700 words) and how many enquiries about availability they receive from existing or prospective clients (on average seven a week, ranging from 1 to 20). Both in-house translators were full-time employees who translated for more than five hours a day. 


\subsection{Data Collection}

Fourteen interviews were conducted face-to-face and three via Skype. Each interview lasted between 10 minutes and 2 hours, and the total recording time was 957 minutes.

As mentioned above, the main interview question was "Have your clients ever had disagreements/issues with the quality of your translation?" Once the participants started telling their stories, they were encouraged to give details through questions such as "What did your clients say to you?" and "What did you say to them?" These follow-up questions did not aim to elicit true verbal recall, as verbatim memory is notoriously unreliable (Hjelmquist 1984). Instead the aims of the questions were to encourage the interviewees to elaborate on their stories so that more data would be generated. The participants were allowed to present as many stories as they wished. As a result 93 stories were collected from the 17 participants. The story unit used for analysis was one complete episode of an incident in which the translator had a conflict with his/her client, discussion and negotiation took place, and the dispute came to a closure. Each story was labelled with the participant number and story number i.e., Story 01-01 is the first story produced by Interviewee No. 1. The interviews were recorded, transcribed and analysed in the language used (English or Japanese). I translated the Japanese examples for a reporting purpose and this is indicated by [J].

\subsection{Data analysis}

\subsubsection{Methodological approach}

The study used both qualitative and quantitative methods, supporting qualitative data by quantitative evidence. In the qualitative analysis, two methods of discourse analysis were used: grounded theory (on the macro level) and Discursive Psychology (on the micro level). Grounded theory, originally developed by Glaser and Strauss (1967), was chosen as it analyses empirical data to identify commonly occurring concepts and categories in an inductive manner, aiming eventually to generate a theory which is grounded in the data. The method involves coding passages of the transcribed texts with concepts and then gradually grouping the concepts into broader, more abstract concepts. In coding the texts, interpretation of the meaning was necessary. For this purpose, the principles of Discursive Psychology (DP) (Edwards and Potter 1992), particularly the Discursive Action Model (DAM) (Edwards and Potter 1993) was used. Unlike traditional experimental psychology, in which talk is treated (with some unavoidable limitations) as a means of observing the state of the speaker's cognitive state, DP, being influenced by Speech Act Theory and Conversation Analysis, treats discursive practice (such as what the speaker says in an interview) as an object of study to observe what they are doing in the social space with the talk. Within this programme DAM uses attribution as a key discursive action in people's talk. Adopting this model, my interviewees were understood to be performing an act of attribution by explaining why a problem occurred in their stories, that is, attributing the cause of the problem to certain factors, or by explaining why their solution was correct, i.e., attributing the success of their translation to certain factors. My aim was to identify what concepts they used in performing this act of attribution. 


\subsubsection{First stage: identifying justification methods}

A close investigation of the data revealed that the translators justified their translational actions in six different ways.

1) By explaining what factors affected the features of the product: Translators justified their translational actions by explaining what factors affected their translational decisions, such as the level of remuneration, time allowed for translation or the translator's knowledge of the specialised domain, suggesting that they did their best to do the job within the constraints.

2) By explaining what policy was followed when translating: Translators said their translational actions followed some kind of rules, whether their own personal policies, shared professional norms like genre convention or what was imposed by clients.

3) By explaining what strategies were used when producing the translation: Translators justified their translational actions by explaining what translation strategies they used in the translation process, implying that the strategies were the best possible options for the circumstances. These include both textual and operational translation strategies.

4) By explaining what criterion was used for judging the quality of translation: Translators justified their translational actions by explaining what criterion they used to judge the translation quality, implying that their criterion was the correct one in the situation. These include grammar rules or stylistic preferences.

5) By reporting what consequence the delivery of the translation induced: Translators justified their translational actions by explaining the outcomes of the dispute which were favourable to the translators, such as that they received another assignment from the same client at a later date.

6) By explaining what caused the dispute: Translators explained that the dispute was caused because of misconduct or misunderstanding on the part of the client. For example, the client's expectation about translation was unrealistic.

In the first stage of the analysis, I coded the data using these six justification methods as labels for coding. More specifically, I identified a text segment in which the interviewee is justifying his/her translation or translational action by attributing a problem or success to a certain factor. I then coded the segment with one of the six labels according to the way he/she did the act of attribution. As a result, between 50 to 161 segments of the data were coded at each label (justification method).

\subsubsection{Second stage: identifying concepts}

The next stage involved coding the data with a different set of labels, i.e., concepts. By judging what concepts were used in the translators' acts of attribution, relevant segments of the stories were coded with the concepts. The concepts used here were not pre-determined, but were generated from the stories by identifying similarities and differences across different stories, i.e., using what is called a "constant comparative method" in grounded theory's terms (Glaser and Strauss 1967: 105-113). I compared one story to another or one segment of a story to another in the same story, checking if the next incident added a new aspect or confirmed the old. If a similar aspect was identified, I considered that they could be grouped as a single category. For example, the concepts of 'dictionary' and 'interpretation,' which both had only one passage coded at them, were eventually merged into the concept of 'meaning' 
after reading the surrounding parts of the transcripts and confirming that both concepts were used in the same sense as 'meaning.'

In this way, by the end of the second analysis stage, the concepts were eventually grouped into 37 concepts (Table 1). During the analysis, care was taken not to miss any concepts even if they seemed to be trivial to the purpose of the study, in case they might have any significance in the later stage of analysis. The results thus include concepts such as "Well-being" (one interviewee said jokingly that his translation quality suffered if he had a hangover). Section 4 will illustrate how these concepts were generated and coded.

TABLE 1

Concepts generated (in alphabetical order)

\begin{tabular}{|l|l|}
\hline 1. Authority & 19. Preference \\
\hline 2. Consistency & 20. Professionalism \\
\hline 3. Context & 21. Purpose \\
\hline 4. Culture & 22. Qualification \\
\hline 5. Discussing Translation & 23. Reader \\
\hline 6. Disposition of Participants & 24. Reference Material \\
\hline 7. Effect of Use of Translation & 25. Relationship \\
\hline 8. Experience & 26. Repeated Commission \\
\hline 9. Feedback & 27. Responsibility for Consequence \\
\hline 10. Instruction & 28. Role of Participants \\
\hline 11. Knowledge of Language & 29. Satisfaction (or lack of -) \\
\hline 12. Learning & 30. Source Text \\
\hline 13. Linguistic Features & 31. Specialisation \\
\hline 14. Meaning & 32. Technology \\
\hline 15. Money & 33. Terminology \\
\hline 16. Name of Translator & 34. Text Type \\
\hline 17. Native Speaker & 35. Time and Effort \\
\hline 18. Natural versus Literal Translation & 36. Translator's Note \\
\hline & 37. Well-being \\
\hline
\end{tabular}

In the rest of this article, the names of the concepts are capitalised.

\subsubsection{Third stage: identifying prominent concepts}

In the first two stages of the analysis, the justification methods were identified and the concepts were generated qualitatively and the data was coded using them as labels. In the third stage of the analysis, the degree of significance of the concepts was measured quantitatively. This was done by measuring the number of occurrences of overlaps of coding between each of the justification methods and each of the concepts identified above. Here is an example of overlaps of coding.

A segment of the data: "They (the client) were used to translating in this very, very literal, almost word-for-word sense, which was not well-written English but that's what Company S (the client) liked."

First stage coding: Justification method 1) By explaining what factors affected the features of the product

Second stage coding: Concept 1) Authority (because the interviewee is talking about the client's preference as a factor which affected the textual feature of translation) and 18) Natural versus Literal Translation (because the interviewee is talking about the literalness of the translation). 
As a result, there are two occurrences of overlaps of coding in this segment of data:

Overlap No. 1: Justification method 1) x Concept 1) Authority

Overlap No. 2: Justification method 1) x Concept 18) Natural versus Literal Translation.

In this stage of the analysis, the frequency of overlaps was measured in two ways: a) by counting the number of stories in which at least one occurrence of such an overlap happened; b) by counting the actual number of occurrences of overlaps in all stories. The frequency of overlaps was measured in these two ways to avoid any influence of personal discursive tendencies on the results. To test if there was any imbalance in the numbers of overlaps of coding between methods a) and b), a scatter plot diagram was generated (Figure 1). The diagram shows that all the concepts are located in a near-linear manner, which suggests that no extreme influence from personal discursive tendencies exists in the outcomes.

\section{FIGURE 1}

Correlation of occurrences of overlapping coding between the number of stories and the number of segments

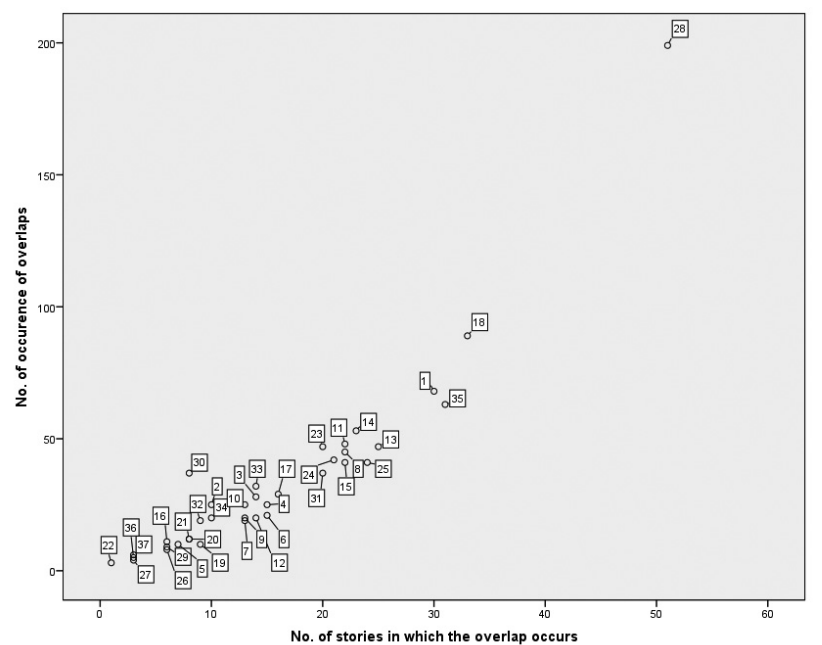

The number of each plot corresponds to those in Table 1 .

Judging from this diagram, the ten most significant concepts (i.e., the ones which are located nearer the top right-hand corner) are:

- Role of Participants

- Natural versus Literal Translation

- Time and Effort

- Authority

- Linguistic Features

- Meaning

- Relationship

- Knowledge of Language

- Experience

- Money
No. 28 in Figure 1

No. 18

No. 35

No. 1

No. 13

No. 14

No. 25

No. 11

No. 8

No. 15 
In what follows I will explain these concepts, placing a particular focus on the most significant one, Role of Participants, as it is by far the most prominent concept amongst all.

\section{Findings and discussion}

\subsection{The Role of Participants: the most prominent concept}

The concept of the Role of Participants is by far the most notable concept used by the participants (198 passages in 51 stories). The participants who were discussed in the interviewees' accounts include: the translator; the translation agency (and its project manager); the client (this sometimes corresponds to a translation agency and other times to an end-client who commissions a translation agency to translate a document); the direct client (so called when the commissioner of a translation does not use a translation agency); the user of translation; the proof reader; the editor and the source text author.

The reason why the concept of the Role of Participants was by far the most popular is that the concept was regularly used in conjunction with other concepts. For example, in Story 01-01, the interviewee said that the translation agency gave him a Source Text which was not typed clearly and, as a result, he mistranslated.

$[\ldots]$ the original was not very legible ${ }^{[1]}$. There was one place $[\ldots]$ where it said this thing needs to be [...] tightened but I misread the character as it needs to be loosened. Shimeru (tighten) and yurumeru (loosen), if the character is blurred, it's easy to be mistaken. And so I translated it in the wrong way. Their client spotted the error [...] and they complained to me about this. And I said, "Well fine, give me a better copy next time $^{[2]}$." (From Story 01-01)

In the early part of the passage (the underlined segment [1]), Interviewee 01 attributed his mistake to the poor quality of the source text. Thus, this segment was coded at the justification method 'Factors which affect features of translation' and the concept Source Text. But in underlined segment [2], he developed this concept into an aspect of an action (or here, rather, the lack of it) by the translation agency, saying that they did not supply a clear copy of the Source Text to him. Interviewee 01 said he had said to the agency, "Well fine, give me a better copy next time." One would not assume that these are the exact words he used, but this utterance can be interpreted as showing that the interviewee attributed his mistranslation to the fact that he did not receive a better copy of the Source Text, i.e., the agency did not fulfil their role.

In Story 02-01, told by a technical translator, the end client did not supply any terminology list for the translation of a text about a clinical data input system so the translator used the terminology of her choice in her translation. After delivering the translation, the translation company contacted her.

They told me how the end client amended the translation and asked me "what do you think about this?" So I thought, "Why are you asking ME?" [...] Whether to use "screening failure" or "screening slip" is what the end client needs to decide ${ }^{[1]}$. They did not supply me with a terminology list at the beginning ${ }^{[2]}$ so how can I comment on their amendment? (From Story 02-01) [J] (The capital letters indicate an emphasis in the speech.) 
Here, Interviewee 02 used the concept of Authority and Terminology (the client should decide which term is to be used) to justify her translation while explaining the factors which affected the features of translation (underlined segment [1]). Then she developed the concept further into the concept of the Role of Participants by saying that the end client did not do what she thinks they should have done (underlined segment [2]).

The interviewees also talked about their own roles, mostly by claiming that other participants had wrong ideas about them.

I had to go through these the next MORNING and I had no idea of the context until I saw these ${ }^{[1]}$ and I thought this is SO MUCH OF THIS. I can't do this in four hours ${ }^{[2]}$. But I went anyway and I said, "Well look, I'll do what I can for you." And then I was there for two hours looking at these documents and, after two hours the client, the solicitor, said, "I'm sorry. This is too slow. ${ }^{[3]}$ You are not making any progress." (From Story 04-01)

In this account, Interviewee 04 talked about his experience of being called into a solicitor's office to translate Japanese documents into English. Here, again, Interviewee 04 justified his translation by explaining what factors affected the features of translation (insufficient time for the job) and the translator's background knowledge about the particular topic of the translation (legal issues) was limited due to insufficient time for preparation. Here he used the concepts of Time and Effort and Context (the underlined sections [1] and [2]) and then he said the client had a wrong perception of what the translator is capable of ([3]), which was coded as Role of Participants.

Probably because of the interview question (asking about conflict situations), the concept of Role of Participants was most often used in a negative sense, i.e., for explaining that other participants did not fulfil their roles properly. However, the interviewees sometimes used the concept in a positive sense, commending how other participants fulfilled their roles and explaining how that facilitated the translators' producing good quality translation. In the examples below, the translators appreciate the way the project managers maintained their relationship with their clients, which they assume is the role project managers ought to play. Therefore, those examples were coded under both the concept of Relationship and the concept Role of Participants.

The project manager was very articulate. When I pointed out some problems, she asked me to give her some specific pieces of information like this and this and this, and once the information is supplied, she sent me an email asking me, "I'm going to send this email to the client. Are you happy with this?" (From Story 02-0)][J]

The agency totally accepted what I said. They said, "We understand now. We'll send your comments back to the client and see how they react." So I think the agency forwarded my report directly back to the client. (From Story 10-1)[J]

\subsection{Relationships with sub-concepts}

Judging from its quantitative prominence, the concept of Role of Participants situates itself at a higher level than other concepts. In other words, in translators' discourse, Role of Participants is a higher-order concept to which other narrower concepts (or sub-concepts) relate. The link between Role of Participants and other concepts was measured quantitatively by counting the number of overlaps of coding (how many 
segments of texts were coded by the concept of Role of Participants along with other sub-concepts). The top ten concepts are shown in Table 2.

TABLE 2

Ten most related concepts to the concept of the Role of Participants

\begin{tabular}{|l|c|}
\hline Related concepts & $\begin{array}{c}\text { No. of overlaps of coding with the concept } \\
\text { of Role of Participants }\end{array}$ \\
\hline Relationship & 30 \\
\hline Knowledge of Language & 26 \\
\hline Time and Effort & 24 \\
\hline Authority & 18 \\
\hline Source Text & 17 \\
\hline Natural versus Literal Translation & 16 \\
\hline Instruction & 14 \\
\hline Money & 13 \\
\hline Native Speaker & 13 \\
\hline Experience & 12 \\
\hline
\end{tabular}

What follows is a description of how these sub-concepts relate to the concept of the Role of Participants.

\subsubsection{Relationship}

The interviewees were particularly conscious of the relationships between the participants in translation. An equal relationship between participants is ideal, though it does not obtain consistently (for example, when the project manager and their client are in an imbalanced power relationship), affecting the translator's operation and eventually the quality of translation. The translators also often talked about the relationships which they themselves were not part of, such as the relationship between the project manager and the end client. Sometimes they even talked about staffing problems in a translation company such as fast staff turnaround. This suggests that successful translators work in the network of participants while having a bird's eye view of the network and being aware of its implications for their practice. For them, quality cannot be explained by recourse to the textual features alone; instead, human factors have to be brought into the discourse.

\subsubsection{Knowledge of Language}

Knowledge of Language is a concept which was identified as opposed to knowledge of translation. This sub-concept demonstrates the interviewees' belief that translation is a special kind of linguistic activity which is clearly not a simple linguistic transfer between two languages. However, they are frustrated that other participants often believe that good knowledge of language is all that is required for successful translators. Particularly, people with quite a good knowledge of foreign language(s) tend to overestimate their own ability to assess the quality of translation, which annoys translators and often causes a dispute. The underestimation of the complexity of the activity of translation, they say, is embodied in the unfairly low pay for translator (which is represented in the sub-concept of Money). 


\subsubsection{Time and Effort}

This sub-concept was generated as a result of merging two initial concepts ('Time' and 'Effort'), which implies that the translators seem to measure their (and other participants') efforts in terms of how much time is spent. They seem to think it vital that all participants in translation spend sufficient time to fulfil their own roles to enable the translator to produce the best possible translation. In addition, translators think that other participants overestimate what translators should be able to do in a short timeframe.

\subsubsection{Authority}

The concept of Authority expressed by the interviewees in the present study can be compared with the concept of authority linked to Lefevere's notion of patronage, particularly where patronage is "undifferentiated," i.e., "in a situation in which different patrons represent different, conflicting ideologies" (Lefevere 2012: 206). My interviewees' discourse on authority suggests that they think the ownership of Authority should change depending on the situation, i.e., it should belong to either the translator or other participants. For this reason, Authority is a fluid and complicated sub-concept for translators.

The most notable tendency amongst my interviewees with regard to Authority is that translators do not wish to exert their own authority in the process of producing the translation. The interviewees often expressed their wish that other participants in translation such as the project manager should exercise proper control over translation projects. One way of doing this is to produce clear Instruction(s) to translators. When it comes to translation quality, they often think it is the client's or the proof reader's role to exercise Authority over the final decisions about the translation relating to, for example, Terminology or the register of the text. The accounts suggest that my interviewees, though they are commercially successful translators, do not wish to claim ultimate Authority over their translations. Instead, they recognise they are part of a team which engages in translation and that translation is an activity which can be realised successfully only when all participants play their own roles appropriately. In doing so, the translators seem to accept quite willingly their rather passive role in relation to other participants. However, the analysis also revealed an opposite tendency for translators to express a wish for higher Authority over the translation process, in the context of the naturalness and literalness of the textual features of translation. As Natural versus Literal Translation forms another concept that was often used by the interviewees, I will discuss this issue separately below.

\subsubsection{Natural versus Literal Translation}

This opposition was used when the translators justified their translation quality based on the degree of either naturalness or literalness of the translated text. I use the terms 'natural' and 'literal' here as these are the actual terms the translators used often, but the concepts were also expressed using expressions such as, for natural translation, "fluent," "good English" or iyaku (a common Japanese word which literally means "sense translation"), and for literal translation, "unnatural," "direct," "word-for-word" amongst others. There are many terms in Translation Studies which relate to these 
concepts, but the terminological or even fine theoretical differences are not my concern here. As long as the concept is expressed by the translators using the following assessment criteria, their accounts were coded at this concept. The criteria are that the Source Text (ST) and target text (TT) are similar in one or both of the following respects: 1) the extent to which the TT is recognised as sounding 'right' and not 'strange' by Native Speakers (a related sub-concept); and/or 2) how much information contained in the ST is presented in the TT using surface linguistic representation (i.e., words).

The translators had a clear tendency to wish to have higher Authority for final decisions about textual features when they think it appropriate to produce a naturalsounding rather than a very literal translation. This situation occurred mainly when the source text was of a creative type such as marketing or tourism materials. For example, talking about his assignment to produce a translation for an Englishlanguage tourist magazine, an interviewee showed a positive attitude about gaining Authority, as the next quotation shows.

They [the translation agency] were actually really constructive during the project and they did give me quite a bit of creative freedom. Because there's not always the space to translate everything so I was obviously capturing important information but as well to be a little bit more fluent with the sentence structure and how much turned into English. So I actually really enjoyed this project. (From Story 08-02)

Translators seem to enjoy having this type of Authority in the translation process, which contrasts with the passive attitudes towards the concept of Authority which we observed earlier. The concept of Authority is a prominent one in translators' discourse, but how it is used to justify their translations is fluid. Furthermore, through the concept of Authority, the concepts of Natural and Literal Translation seem to be clearly and closely linked to the concept of Role of Participants as it is the role of the project manager, according to the translators, to decide what Authority the translator should have in the translation project. The concepts of Role of Participants, Authority and Natural versus Literal Translation seem to be related in a very intricate manner.

\subsection{Discussion}

Section 2 described prominent classroom discourses (theories) and Section 3 explained how commercially successful translators theorise their translation. When these two discourses are compared, three points come to our attention: two concerning similarity between them, and one concerning dissimilarity.

First, the translators' discourse presents a clear similarity with the principles of the theory of translatorial action (henceforth TTA) developed by Holz-Mänttäri (1984) in that they both focus on the actions and responsibilities of participants in translation, rather than on the products of translation, claiming that, in order for a successful production of translation, participants involved in the translation need to "agree (explicitly or implicitly) on who is responsible for which tasks" (Schäffner 2011: 159). Although TTA has been criticised for presenting an ideal translational situation, not a description of a real situation, and hence as lacking in empirical evidence (Schäffner 2011: 160), the translators' discourse identified in the present study can contribute such empirical evidence. In the educational setting TTA is being taught 
by $27.8 \%$ of translation teachers, being the $19^{\text {th }}$ (out of 39) most popular theory in the classrooms (Sakamoto 2013: 54). Although TTA is not one of the most prominent theories according to my survey, it can be assumed that, because of its nature, the framework of TTA is actually being used more often in teaching, not in the form of an explicit theory, but as a tacit framework for more practical teaching of translation such as role-playing exercises, where students play different roles in the translation process such as translator, proofreader or project manager, to simulate a professional scenario. Role-play exercises are now one of the "standard methods or techniques used with small groups, ... being the most frequent or most useful in translator training" (Kelly 2005: 101). Therefore, it would be reasonable to deduce that TTA serves as a conceptual contact point between the subcultures of professional translators and scholars and teachers in current translation education in the UK.

Second, the fact that the concept of Natural versus Literal Translation was the second most prominent concept in the translators' discourse echoes the survey result that a majority of translation teachers teach this dichotomy, though under different labels $(87.5 \%$ as "domesticating vs. foreignising translation," $83.3 \%$ as "dynamic vs. formal equivalence," $58.3 \%$ as "semantic and communicative translation," $41.7 \%$ as "overt vs. covert translation" and $37.5 \%$ as "documentary vs. instrumental translation") (Sakamoto 2013: 54). This suggests that this dichotomy of Natural versus Literal Translation is shared by both translation teachers and practicing translators, occupying an important place in their respective discourses. However, my analysis also suggests that the way the translators explained their practice is rather complex. For example, a factor such as Authority (how much authority the translators feel they have in the translation project in relation to other translation participants) seems to affect their translation decisions about the degree of naturalness/literalness of the textual features of translation. If such external factors are affecting the textual features of translation in the real world, it would be important to recognise the relationships between the factors and textual features and reflect them in classroom teaching. The concepts identified in the present study will offer a list of such factors.

Third, I would like to go beyond the comparison of discourse between professional translators and academics and teachers for a moment and consider the translators' discourse in the context of recent industry trends, which seems to be particularly revealing, and also alarming. The translators' discourse presents a set of norms which they believe should be in operation in professional environments in order for them to do a good job. The norms are particularly related to the role of the project manager of a translation company or their client, which can be summarised to be: 1) proper provision of work material, 2) provision of clear instruction; 3) appropriate personnel and time management; 4) implementation of adequate quality control (QC) systems; 5) maintenance of necessary communication between all parties (including translators and end-clients). With regard to their own roles, the interviewees often talked about how their roles were misunderstood by other participants in translation. The misunderstandings include: i) A translator can translate very quickly; ii) A translator is willing to work for small remuneration; iii) A translator understands what kind of translation the client wants without proper instructions; iv) A translator can produce a translation even if the ST is not in order. Removing these misunderstandings would produce their ideal working conditions, e.g., translators should be given sufficient time to produce good quality translation, etc. When 
this set of 'ideal' conditions presented by the translators is compared with what seems to be the recent trend in the industry, some discrepancies are notable. For instance, my interviewees stressed the importance of good relationships between the participants in translation for the production of successful translations. Translation (at least non-literary translation) is now increasingly undertaken by a virtual team (RodríguezCastro 2013; Stoeller 2011), where the translator is located remotely from other participants and only connected virtually, for instance by email. In these conditions, shaping good personal relationships with other participants may be an unrealistic wish on the part of translators. The advent of the paid crowdsourcing business model has also had significant impacts on the translation industry (Garcia 2015), including on communication between participants in the translation process. Where this new model is used, translator bids for translation assignments via the translation company's Intranet interface. If the bid is successful, they are commissioned to undertake the assignment, again via the Intranet interface. In this digital environment, even an exchange of email is unnecessary, and it is difficult for translators to establish good personal relationships with the project manager or the client in this environment. The issue of speed is another area to note. My interviewees often used the concept of Time and Effort as a factor which influences the textual features of translation. However, the demand for quick turnaround of translation is extremely high in the translation industry currently, particularly given the increasing use of machine translation. How can translators secure the time they think is necessary to do a good job in this increasingly speed-conscious working environment?

There is an emerging body of literature which highlights this gap between translators' ideal working conditions and actual professional environments. This work covers, for example, Danish translators' frustration about the lack of recognition of their expertise by the general public (Dam and Zethsen 2008), the importance of the physical location of translators and their contacts with other participants (e.g., readers) for their self-esteem and professional pride in the context of Finnish EU translators (Koskinen 2008), and Finnish freelance audiovisual translators' lack of agency when they are forced to play roles assigned to them by their employers (Abdallah 2011). The research foci of these studies overlap with some of the concepts identified in the present article, such as Knowledge of Language (like the Danish translators, my translators feel that other participants sometimes do not acknowledge that translation requires more than just good knowledge of language), Relationship (like Koskinen's EU translators, the remote location of the translators from other participants and the lack of close and cooperative Relationships between participants adversely affect the self-esteem of translators) and Time and Effort and Authority (like Abdallah's audiovisual translators in Finland, my translators showed a passive attitude about having Authority in translation projects while claiming Authority where they think natural-sounding translation is suitable for the target text. They also feel that they are sometimes under pressure to work in an unfairly short timeframe).

These studies situate themselves in sociological translation studies, dealing with such things as agency of actors in translation or the network of the actors. In my survey of translation teachers, only $10 \%$ said they explicitly teach sociological translation theories (eight out of 93 teachers said so with seven of them mentioning Bourdieu and two mentioning Latour) (Sakamoto 2013: 54-55). Of course sociological notions have been discussed in more traditional translation discourse such as in norm theory 
of translation (e.g., Chesterman 2000; Toury 1995), but the more recent sociological turn in translation studies has shed light on translators and, importantly, other actors in the translation process more explicitly. The translation industry is going through rapid changes, and in this climate, I agree, like Jääskeläinen, Kujamäki, et al. (2011: 152), with Bernardini's opinion that the core aim of translation education is to "favour the growth of the individual, developing her cognitive capacities, and those attitudes and predispositions that will put her in a position to cope with the most varying (professional) situations" (Bernardini 2004: 20; my emphasis). Considering how my interviewees, who are commercially successful translators, theorised their translation, more explicitly sociological-oriented theories may deserve more attention in classroom discourse so that the teaching can not only prepare students for the recent trends of the industry, but also to nurture their capacities and attitudes to cope with any future changes in their professional life. Sociological theories of translation can play an important role as a meeting point for the professional world and academia.

\section{Conclusion and future research}

This article reported the results of a study which investigated what concepts professional translators used to justify their translation. The most prominent concept used in the translators' theorisation was the Role of Participants. The analysis also revealed that some sub-concepts were closely related to this main concept in the way their accounts were developed. Those sub-concepts included Relationship, Knowledge of Language, Time and Effort, Authority and Natural versus Literal Translation. The article described the relationships of these sub-concepts and the higher-order concept of the Role of Participants.

The results were then compared with classroom discourses of translation, which highlighted three points. First, the principles of the theory of translatorial action developed by Holz-Mänttäri (1984) seem to be providing the intersection of the professionals' discourse and classroom discourse. Second, the dichotomous concept of translation (in the interviewees' terms, Natural versus Literal Translation) is another prominent discourse shared by professional translators and translation teachers. In addition, the professional discourse displayed some intricate relationships between the concept of Natural versus Literal Translation and other sub-concepts such as Authority. Third, the professional translators' concerns about what roles different participants of translation should play in order to achieve high quality translation seems to be increasingly diverging from the current industry trend. I argued that this gap is important for translation teachers to recognise in order to provide adequate teaching to prepare students for the changing climates of the translation industry. For that purpose, sociological theories of translation will offer a good discussion space in the classroom.

The study described a particular subculture of translators, i.e., commercially successful Japanese/English translators in the UK. The study showed that the translators' concerns are very much related to other participants in translation in addition to the translator him/herself. Future research may focus on these other participants, particularly project managers of translation companies, who were talked about extremely often by my translators, to cross-refer their views and behaviours with those of translators. Also, the present study involved Japanese/English translators 
only. Investigating discourses of translators of different language combinations may reveal different concepts, thus different translation subcultures. In addition, further analysis of the data according to their language direction or location of their clients may shed light on how British and Japanese cultural elements influence translators' perception and explanation of their work, but this will be left for future work due to space limitation.

\section{ACKNOWLEDGMENTS}

I would like to express my gratitude to the translators who generously took time out from their busy schedule to take part in this study.

This article derives from a PhD study which was funded by a University of Leicester PhD studentship, a Toshiba International Foundation Graduate Research Studentship and a Santander Travel Award.

\section{REFERENCES}

AbDAllah, Kristiina (2011): Quality problems in AVT production networks: Reconstucting an actor-network in the subtitling industry. In: Adriana Serban, Anna Matamala and JeanMarc Lavaur, eds. Audiovisual Translation in Close-up: Practical and Theoretical Approaches. Bern: Peter Lang, 173-186.

Bernardini, Silvia (2004): The theory behind the practice: Translator training or translator education? In: Kirsten MalmkjÆR, ed. Translation in Undergraduate Degree Programmes. Amsterdam: John Benjamins, 17-29.

Burr, Vivien (2003): Social Constructionism, 2nd ed. Hove: Routledge.

Chesterman, Andrew (2000): Memes of Translation: The Spread of Ideas in Translation Theory. Amsterdam: John Benjamins.

Collins, Harry (2007): Rethinking Expertise. Chicago: University of Chicago Press.

Dam, Helle V. and Zethsen, Karen K. (2008): Translator status: A study of Danish company translators. The Translator. 14(1):71-96.

Edwards, Derek and PotTer, Jonathan (1992): Discursive Psychology. London: SAGE.

Edwards, Derek and Potter, Jonathan (1993): Language and causation: A discursive action model of description and attribution. Psychological Review. 100(1):23-41.

GarCia, Ignacio (2015): Cloud marketplaces: Procurement of translators in the age of social media. JoSTrans. (23):18-38.

Glaser, Barney G. and Strauss, Alselm L. (1967): The Discovery of Grounded Theory: Strategies for Qualitative Research. Chicago: Aldine.

Gubrium, Jaber F. and Holstein, James A. (2009): Analyzing Narrative Reality. Los Angeles; London: SAGE.

HJelmQuist, Erland (1984): Memory for conversations. Discourse Processes. 7(3):321-326.

Hölz-Mänttäri, Justa (1984): Translatorisches Handeln. Theorie und Methode. Helsinki: Academia Scientiarum Fennica.

JÄÄSKelÄInEn, Riitta, KUjAmÄKI, Pekka and MÄKisalo, Jukka (2011): Towards professionalism - or against it? Dealing with the changing world in translation research and translator education. Across Languages and Cultures 12(2):143-156.

Kelly, Dorothy (2005): A Handbook for Translator Trainers: A Guide to Reflective Practice. Manchester: St. Jerome.

Koskinen, Kaisa (2008): Translating Institutions: An Ethnographic Study of EU translation. Manchester: St. Jerome.

Lefevere, André (2012): Mother courage's cucumbers: Text, system and refraction in a theory of literature. In: Laurence Venuti, ed. The Translation Studies Reader, 3rd ed. London: Routledge, 203-219. 
Murray, Michael (2003): Narrative psychology. In: Jonathan A. SMIth, ed. Qualitative Psychology. London: SAGE, 111-131.

PRUNČ, Erich (1997): Translationskultur (Versuch einer konstruktiven Kritik des translatorischen Handelns). TextconText. 11(1):99-127.

PrunČ, Erich (2007): Zur Konstruktion von Translationskulturen. In: Larisa SCHIPPEL, ed. Translationskultur - ein innovatives und produktives Konzept. Berlin: Frank \& Timme, $19-41$.

Pyм, Anthony (2010): Exploring Translation Theories. London: Routledge.

Rodríguez-CAStro, Mónica (2013): The project manager and virtual translation teams: Critical factors. Translation Spaces. 2:37-62.

SАкАмото, Akiko (2013): What theories are taught in translation classrooms and why?: Survey results in the UK and Ireland. Invitation to Translation Studies. 9:47-62.

SChäFfner, Christina (2011): Theory of translatorial action. In: Yves Gambier and Luc van Doorslaer, eds. Handbook of Translation Studies Vol 2. Amsterdam \& Philadelphia: John Benjamins, 157-162.

Stoeller, Willem (2011): Global virtual teams. In: Keiran Dunne and Elena Dunne, eds. Translation and Localization Project Management: The Art of the Possible. Amsterdam \& Philadelphia: John Benjamins, 290-317.

Susam-Sarajeva, Şebnem (2002): A 'multilingual' and 'international' translation studies? In: Theo Hermans, ed. Crosscultural Transgressions: Research Models in Translation Studies II: Historical and Ideological Issues. Manchester: St. Jerome, 193-207.

Toury, Gideon (1995): Descriptive Translation Studies and Beyond. Amsterdam: John Benjamins.

UlRYCH, Margherita (2005): Training translators: Programmes, curricula, practices. In: Martha Tennent, ed. Training for the New Millennium: Pedagogies for Translation and Interpreting. Amsterdam: John Benjamins, 3-33. 